\title{
A Pragmatic Study of Fallacy in David Cameron's Political Speeches
}

\author{
Fareed H. H. Al-Hindawi \\ Dept. of English, Faculty of Education, Babylon University, PO Box 1, Babil, Iraq \\ E-mail: fareedhameed@gmail.com
}

Musaab A. Alkhazaali (Corresponding author)

Dept. of English, Faculty of Languages, Kufa University, 35 Sq., Najaf, Iraq

E-mail: rahmanmusaab@yahoo.com

Duaa Al-Awadi

Dept. of English, Faculty of Education, Babylon University, 27 Sq., Babil, Iraq

E-mail: noor.an7525@gmail.com

Received: May 15, 2015 Accepted: June 11, 2015 Published: July 12, 2015

doi:10.5296/jsss.v2i2.7616 URL: http://dx.doi.org/10.5296/jsss.v2i2.7616

\begin{abstract}
Fallacy as a derailment of strategic maneuvering can be defined as the process of issuing a defective argument (when subjected to certain criteria) to support and strengthen a previously issued one for purposes of persuasion. However, fallacy is a broad topic that has been approached from different perspectives. Several studies have attempted to tackle it pragmatically. Yet, those attempts have suffered from many gaps and drawbacks which have characterized them as insufficient accounts in this regard. Many pragmatic aspects related to fallacy, like its pragmatic structure and the strategies used for issuing it, have not been given their due attention. Hence, this work has set itself the task of dealing with this problem. Precisely, it concerns itself with the aims of finding out the pragmatic structure and pragmatic strategies of fallacy in David Cameron's, the British prime minister, war and electoral political speeches. In association with these aims, there is a development of a pragmatic model for the analysis of these two aspects in the speeches scrutinized. This model is built
\end{abstract}


upon several models introduced by several scholars in addition to some contributions made by the researchers themselves. The validity of the developed model is tested by means of analyzing fourteen fallacious situations taken from David Cameron's war and electoral political speeches. The analyses conducted have proved that the model developed is workable. Besides, they have yielded various results among which is that fallacy is a process composed of various stages. Each stage is distinct for its pragmatic components and strategies.

Keywords: Political speeches, Pragmatics, Fallacy, Argument

\section{Introduction}

Fallacy has been the main concern of various studies that have dealt with it from different perspectives: logical, dialectical, pragma-dialectical and pragmatic ones. But these accounts have suffered from many drawbacks like their failure to identify the pragmatic structure and strategies of issuing fallacy. Addressing this problem, this study has targeted the following aims: (1)finding out the pragmatic structure of fallacy in David Cameron's war and electoral political speeches, (2) pinpointing the main pragmatic strategies of issuing fallacy used in those speeches, and (3) developing a pragmatic model for the analysis of the pragmatic structure and strategies of issuing fallacy in those speeches.

In relation to the above aims, it is hypothesized that: (1) fallacy is a process composed of various stages, each stage is distinct for its pragmatic components, (2) David Cameron, the British prime minister, tends to use certain strategies of issuing fallacy more than others. To fulfill the above aims and verify the above hypotheses, the following procedures are adopted: (1) analyzing fallacious situations in the political speeches under study by means of the model developed for this purpose, (2) using a statistical method, represented by the percentage equation, to calculate the results of analysis.

\section{Fallacy}

\subsection{Definition}

Fallacy assumes a crucial part of our daily life exchanges; people make fallacies everywhere in offices, at homes, in schools, ads, media...etc. Therefore, Fallacy is at the top of every fully fledged argumentation theory. Rated so highly, the study of fallacy begins as early as argumentation and logic emerge. Since that time, there is a kind of disagreement over the definition of fallacy. This inconsistency and disagreement have led to the emergence of various approaches, theories and definitions of the term fallacy.

Scholars differ in approaching and viewing fallacy. Some, like Aristotle and the sophists, study fallacy from a logical perspective. Others, like Hamblin (1970) prefer to approach it dialectically. For Eemeren and Grootendorst (1999), fallacy is a pragma-dialectical perspective which can be regarded as a "derailment of strategic maneuvering". Still, others approach fallacy pragmatically. In this respect, Walton (1995, p. 23) defines fallacy as: "an argument (or at least something that purports to be an argument); that falls short of some standard of correctness; as used in a context of a dialogue; but that, for various reasons, has a semblance of correctness about it in context; and poses a serious obstacle to the realization of 
the goal of a dialogue".

In 1992, Walton observed that fallacy, in any context, was a process having a starting point and an end point. Such an approach, i.e. the process approach, sees fallacy as a dynamic entity that moves through different stages toward a collective goal based on the collaborative conversational postulates that govern how moves are made during the process (Walton and Reed, 2003, p. 12). The process view to fallacy comes from the purpose or the intention behind issuing fallacy. Walton (2007, p. 159) points out this intention by viewing fallacy as a deliberately crafted tactic of persuasion.

When combining Walton's (1992) view to that of Eemeren and Grootendorst's (1999) in addition to the one presented by Walton (2007) fallacy can be seen by the current work as a derailment of strategic maneuvering that comes through issuing a fallacious argument (an argument that violates a certain rule of correctness) in support of a previously issued argument and it is appealed to as a deliberately crafted tactic of persuasion.

\subsection{Strategic Maneuvering and Fallacy}

The nature of fallacy as an argumentative tactic is difficult to be understood. Some think that it is a deceptive tactic. Others do not. Aristotle (Cited in Walton (1995, p. 1), for example, defines fallacy as a "deliberate deceptive tactic of argumentation used to trick and get the best of a speech partner in a dialogue unfairly".

For Eemeren and Houtlosser (1999, p. 164) fallacy is not a trick. To explain their view in this regard, they introduce what is called as 'strategic maneuvering' to do justice to " the fact that engaging in argumentative discourse always means being at the same time out for critical reasonableness and artful effectiveness" (see Eemeren and Houtlosser, 2002, p. 11). They (Eemeren and Houtlosser, 1999, p. 14) define fallacy as "derailment of strategic maneuvering where rhetoric gains upper hand over dialectics or vice versa". In the current work, fallacy is believed to occur when the arguer has access to means of effectiveness (rhetoric) at the expense of reasonableness. How reasonableness is diminished and effectiveness is increased is discussed in (2.3.2).As for strategic maneuvering it seems to have three aspects that are revealed throughout the process of issuing fallacy. They are as follows:

\section{Topical Potential}

This dimension involves the arguers to choose topics that best advance their interests, i.e. the arguer should choose the topics which he wants to discuss, prove or disprove from the list of topics available at his disposal (Tindale, 1999, p. 4).

\section{Audience Orientation}

This dimension requires the arguer to adapt to audience demands. This lives up to create some sort of empathy and communion with the addressees (Eemeren \& Houtlosser, 2000, p. 298).

Beard (2000, p. 202) states that there are different ways of adapting to audience demands, the best of which is appealing to deixis of integration which is best represented by the first person 


\section{Macrothink}

deixis.

However, earlier to that, Brown and Levinson (1987) (Cited in Watts, 2003, p. 45) consider showing awareness to the hearer's face as the best means of adaptation which is achieved through the following strategies:

\section{a. Claiming a Common Ground}

According to them, the speaker should realize that he and his addressees belong to some group of people who share specific wants, goals and values. This involves the speaker to show that some of the hearer's wants and desires are also desirable to him.

\section{b. Attending to Hearer's Interests}

This requires the speaker to notice the hearer's wants and needs and behave accordingly.

\section{c. Seeking Agreement}

In order to gain the hearer's empathy, the speaker should agree with what the addressees want or say whatever it is. One of the best strategies of seeking agreement is through raising safe topics.

\section{d. Being Indirect}

Directness causes threat to the hearer's face so the speaker should be indirect in order to avoid such threats.

\section{e. Minimize Imposition}

This strategy involves minimizing the possible imposition carried by the utterance of the speaker. This comes through appealing to certain expressions like (just, exactly, only, merely...etc.) or through intonation or through being indirect.

\section{f. Being Pessimistic}

This involves showing pessimism towards what the speaker wants the hearer to do.

\section{Presentational Devices}

This dimension involves using the best means of impressing the hearer at a certain stage of argumentation. In this regard, rhetorical devices are the most effective means to be employed (Tindale, 1999, p. 5). Of these devices, only the ones expected to appear in the data scrutinized are discussed below:

\section{a. Profound Words}

These are words that have a great impact on the hearer when receiving them, like: (great, terrible, superb, magnificent,...etc.) (Tindale, 1999, p. 23).

\section{b. Padding}

It is the process of adding significant-sounding sentences here and there that in fact say nothing or little(Cavender and Kahane, 2006, p. 163). 


\section{c. Weasel Words}

These are locutions that seem to make little or no change in the content of a certain construction or statement, while, in fact, sucking out all or most of its content (Cavender and Kahane, 2006, p. 163).

Brydon and Scott (2008, p. 391) consider it necessary for the public speaker to present his message accompanied by principles of influence which they consider as the most persuasive presentational devices. Of those principles, only the ones expected to appear in the data under study are discussed below:

\section{i. Appeal to Fear}

They (2008, p. 398) state that emotional appeals such as fear can enhance persuasive effect but must be used carefully and ethically.

\section{ii. Appeal to Interests}

They (2008, p. 79) consider it important for the speaker to show his interest in the addressee's interests and wants.

\section{iii. Reciprocity}

The saying "You scratch my back, and I'll scratch yours" illustrates reciprocity. A reciprocity-based appeal can work in one of two ways in a persuasive speech. Candidates for political office often promise to give something in return for a person's vote. They may promise to reciprocate by proposing legislation, supporting a specific bill, or voicing a concern of their constituency (Brydon and Scott, 2008, p. 391).

\section{iv. Authority}

For public speakers to be persuasive, they should appeal to the judgment of people that represent an authority for the addressees so as to convince them of the topic discussed (Brydon and Scott, 2008, p 392).

\section{v. Commitment}

One of the most effective means of persuasion is making commitments. Speakers should commit themselves to what the addressees want them to do in an attempt to convince them (Brydon and Scott, 2008, p. 393).

\section{vi. Flattery}

Flattery, according to Walton (2007: 34), is one of the most effective means of persuading the addressees.

\subsection{Stages of Issuing Fallacy}

Many scholars adopt the process approach to the study of fallacy as a device of persuasion used in argumentation. Among the first who apply this approach to fallacy is Eemeren and Grootendorst (1999). They believe that fallacy issuance is a process of four stages but their 
approach suffers from certain weaknesses. One of the prominent gaps that distorts their approach, according to Walton $(1995$, p. 25$)$, is that fallacy identification is not clear cut, i.e., there are no clear criteria for fallacy identification and this is one of the reasons why their approach is not adopted by this study. Another scholar who always defends the process approach to fallacy is Walton $(1995,2007)$. He believes that fallacy, in any context, has a starting point and an end point. In this way, as pointed out in (2.1), the process approach deals with fallacy as an entity that moves dynamically through different stages aiming to achieve a collective goal based on the collaborative conversational postulates that govern the way in which moves are made during the process.

The process view to fallacy comes from the purpose or the intention behind issuing it, i.e. fallacy. Fallacy, according to Walton (2007, p. 159), is a deliberately crafted tactic of persuasion. It is presented in the context as a means of influencing the addressee to accept something in the arguments or claims presented mainly before the fallacious argument, i.e. the fallacious arguments are resorted to in order to contribute something to the context in which they occur- to the previous arguments and claims. According to Walton (2007, p. 8), fallacy occurs on three stages: the start-point stage, the argument stage and the end point stage. At the start-point stage, the arguer introduces the main topic in the form of argument(s) trying to persuade the respondent to take action regarding the topic in question.

At the argument stage, the arguer issues the fallacious argument to support the previous argument(s) in a deliberately manipulative way. At the end-point stage does come the role of the respondent in evaluating and responding to the fallacious argument. Such response comes in the form of questioning the argument using the set of critical questions associated with it (ibid). These stages seem to accord with aims of this study. However, they will be adopted but with some modification.

As far as the second stage (argument stage) is concerned, two basic issues need to be clarified: criteria of identifying the fallacious argument and its pragmatic strategies.

\subsubsection{Identifying the Fallacious Argument}

Different models for identifying the fallacious argument can be used. In this section only those that can be utilized in developing the pragmatic eclectic model which is used for analyzing fallacy are discussed below.

However, it seems necessary to firstly decide on the criteria that help in identifying fallacious argument in a certain context. Walton's (1995) and Johnson's (2000) models will be made use of by this study to establish the criteria used for deciding why a certain argument is considered fallacious while the types of fallacious arguments that result from violating the criteria will be adapted in the light of what is proposed by Walton (1995) and Johnson (2000).

\subsubsection{Walton's (1995) Pragmatic Model of Fallacy}

Walton's (1995) model of fallacy aims to solve the problem of identifying fallacy faced by all scholars who preceded him. According to him (1995), fallacy is said to be committed whenever an argumentation scheme or theme is used wrongly in a manner that fouls up the 
right sequence of the moves of the dialogue in which it is used. This means that the concept of fallacy is associated not only with insufficiently supported argumentation scheme or theme but also with the wrong use of them which aims to block the achievement of the goals of the dialogue.

Walton (1995) believes that there should be a distinction between argumentation scheme and theme. He (1995) defines argumentation scheme as "premise-conclusion-inference structure that represents common types of arguments used in every discourse, as well as in special contexts that include deductive, inductive and abductive forms of argument" (see Walton, 2007, p. 26).

As for argumentation theme or what is sometimes called as 'profile of dialogue', Walton (1995) seems to have made use of Krabbe (1992, pp. 277-81) in defining the argumentation theme as an important tool used for identifying fallacious argument. Krabbe (1992, pp. 277-81) defines the argumentation theme as tree-shaped descriptions of sequences of dialectic moves that display the various ways a reasonable dialogue could proceed.

Fallacy committed through the wrong use of argumentation theme is out of the concern of the current study since fallacy, in the current work, is committed through issuing a fallacious argument in support of another argument which is not the case with the argumentation theme as stated by Walton (1995).

As for how fallacy is related to the wrong use of an argumentation scheme, Walton (1995, p. 255) defines fallacy as "an argument that falls short of some standard of correctness as used in a context of dialogue but that, for various reasons, has a semblance of correctness in that context and poses a serious obstacle to the realization of the goal of the dialogue". So the inherent nature of fallacy, according to Walton (1995: 23), lies in the Gricean principle of cooperativeness which, according to Grice (1975), reads as follows: "make your contribution such as is required by the accepted purpose and direction of the talk exchange in which you are involved".

Walton (1995) employs this principle and its maxims to find out fallacies. According to him (1995, p. 231) an argument must be evaluated on two levels: the macro (global) level and the micro (local) level.

\subsection{The Macro (Global) Level of an Argument}

At this level, the argument is evaluated systematically in the context where it occurs. Besides, it is presented as a move or sequence of moves in the context of dialogue so it can be evaluated as fallacious if it twists some scheme of argument rightly used in its context to the advantage of the participant who has made the move (Walton, 1995, p. 235).

Such an account of fallacy takes it for granted that in the context where it occurs, there is some set of maxims that regulate how and where appropriate moves should be presented (Walton, 1995, p. 235). For identifying fallacies at the macro level, Walton (1995) puts the following criteria:

\section{a. Dialectical Relevance}


Walton (1995) intends to define relevance in terms of the argument which in turn can be defined in terms of the context in which the argument is used, i.e. how the argument contributes to the achievement of the goals of that context (Walton, 1995, p. 163).

On this basis, an argument is dialectically relevant if it performs a legitimate function in some stage of the argumentation where it is used. So any argument that doesn't perform a function in the argumentation process or is put in a way that subverts the goals of the argumentation is fallacious. For example, the use of the ad hominem argument in a context where the arguer tries to persuade his respondents of something is fallacious (Walton, 1995, p. 197).

\section{b. Dialectical Shift}

Conversationalists in the course of conversation move from one type of dialogue into another. This is called dialectical shift (Walton, 1995, p. 118). Dialectical shift is not always problematic or fallacious. It does become so when deception or misunderstanding is involved. This happens when one party is unaware of the shift made by the other party who tries to conceal the shift to trick his partner (Walton, 1995, p. 120).

Fallacious arguments of dialectical shifts are not the concern of the present study since they involve certain shift from one type of dialogue to another and the data of the present work are monological in nature.

\subsection{The Micro Level}

At the micro level, the main concern is with the premises and the conclusion(s) of the argument. Accordingly, two criteria for judging fallacious argument are distinguished here: relevance and sufficiency.

However, it seems that Walton's (1995) criteria of the micro level are not useful for developing the model targeted at by this study because they are not sufficient to cover the data of this work as compared to others.

\subsubsection{Johnson's (2000) Pragmatic Model of Fallacy}

Johnson (2000) introduces ideas to solve the problem Walton's (1995) model suffers from. He does so by giving attention to both levels but he gives them different terminology: the illative core and the dialectical tier and his terminology will be adopted by this study from now on because it is, as Ramage (2010, p. 50) states is more representative than Walton's terminology. According to Johnson (2000, p. 34), the fallacious argument is "the argument that violates one of the criteria of a good argument and which occurs with sufficient frequency in discourse to warrant being baptized". Johnsons (2000, p. 208) indicates that fallacious argument should be judged on two levels: the illative core and the dialectical tier. For both levels he puts certain criteria. Thus, according to Johnson (2000, p. 208), an argument could be fallacious if it violates the criteria of the illative core or that of the dialectical tier or both of them. He (2000, p.189) calls these criteria (of both levels) the 'criteria of a good argument'.

\subsection{The Dialectical Tier}


Johnson (2000) includes the dialectical tier alongside with the illative core in judging arguments. The dialectical tier refers to the argument within a structure of dialogue, and to how the argument treats alternative positions and standard objections. Dialectical tier is that part of the argument where the arguer discharges obligations (Johnson, 2000, pp. 90-93). He (2000, p. 206) puts criteria for judging fallacious arguments of the dialectical tier as follows: anticipating an objection to a premise, anticipating other criticisms, dealing with alternative positions. However these criteria will not be adopted by the current work since their use involves dialogue while the data under study are mono-logical.

\subsection{The Illative Core}

Johnson (2000) employs the illative core in judging fallacious arguments and puts criteria for testing its goodness. The illative core according to Johnson (2000, p. 190) refers to the structural level that consists of the elements of the argument; the reasons given in support of the conclusion. He (2000, p. 190) puts four criteria for evaluating fallacious arguments at this level: acceptability, truth, relevance and sufficiency.

\section{a. The Acceptability Criterion}

The first who uses this criterion in evaluating arguments is Hamblin (1970). He (1970, p. 242) states that acceptability is the basic criteria for evaluating an argument. Johnson (2000), in an attempt to define acceptability, states that the acceptability criterion requires that whenever the proponent puts a thesis, he must furnish support for it, and both the thesis and support must adapt to the audience to whom they are presented (Johnson, 2000).

The requirement of acceptability must be understood in terms of a dialectical situation of interacting between a proponent and respondent in a certain context and that is why it is a pragmatic criterion (Johnson, 2000, p. 95).

This criterion is applied to all elements of the argument. When it is applied to a certain premise the arguer must ask himself "is this premise one which my audience is prepared to accept as good" (Johnson, 2000, pp. 200-201).

\section{b. The Truth Criterion}

Johnson (2000, p. 197) makes use of this criterion to judge what arguments to be considered as fallacious and sees it hard to imagine evaluation without resorting to the truth criterion. It is after all the core of communication. According to Johnson (2000, p. 197) this criterion judges the truth versus the falsity of a certain utterance and it is applied to all the elements of the argument and violating it may result in fallaciousness.

\section{c. The Relevance Criterion}

Johnson (2000) employs this criterion to judge the fallaciousness or not of an argument. What is meant by relevance, according to him (2000, p. 200), is the propositional relevance to be distinguished from other types like topical relevance and audience relevance. Relevance, on the illative core, is a property of propositions. It is applied to the evidence presented to support the conclusion. It is context-sensitive, i.e. what is relevant in one context may be not 
in another and this is why it is a pragmatic criterion (Johnson, 2000, pp. 201-2).

\section{d. The Sufficiency Criterion}

The regulation of this criterion is that the premises must provide sufficient support or evidence to prove the conclusion or target claim (Johnson, 2000, p. 205).

Sufficiency, unlike relevance, should be presented to both data and warrant at the same time. What is sufficient in one context or set of circumstances may not be so in another. Accordingly, the data under study will be judged on two levels, to use Johnson's (2000) terminology, the dialectical tier and the illative core. Precisely, for the dialectical tier Walton's (1995) criterion of (dialectical relevance) are used for the identification of fallacious arguments. For the illative core, Johnson's (2000) criteria (acceptability, truth, relevance and sufficiency) are used for identifying fallacious arguments. Figure 1. below illustrates these criteria:

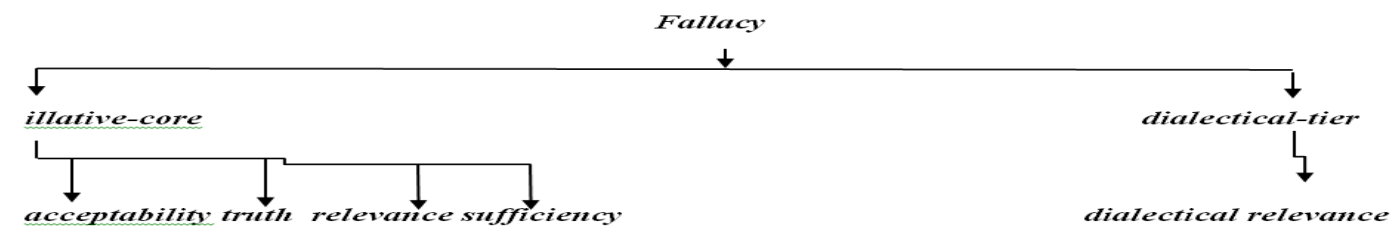

Figure 1. Criteria for Identifying fallacious arguments on the two levels

\subsubsection{Pragmatic Strategies of Issuing the Fallacious Argument}

The criteria of identifying fallacious arguments arrived at in the previous section are also employed as part of the strategies used for issuing the fallacious argument. Generally speaking, the strategies that trigger fallacious argument(s) can be appealed to on two levels: the illative core level and the dialectical tier level.

At the illative core level the arguer can issue a fallacious argument by resorting to the following strategies:
a. Violating acceptability
b. Violating truth
c. Violating relevance
d. Violating sufficiency

At the dialectical tier the arguer commits a fallacious argument if he uses the following strategy: violating dialectical relevance. According to Walton (1995, p. 34) and Johnson (2000, p. 56), violating any one of these criteria leads to diminishing reasonableness for persuasive purposes. This means that, violating any one of these criteria leads to a derailment of strategic maneuvering.

These strategies are best illustrated by Figure 2. below: 


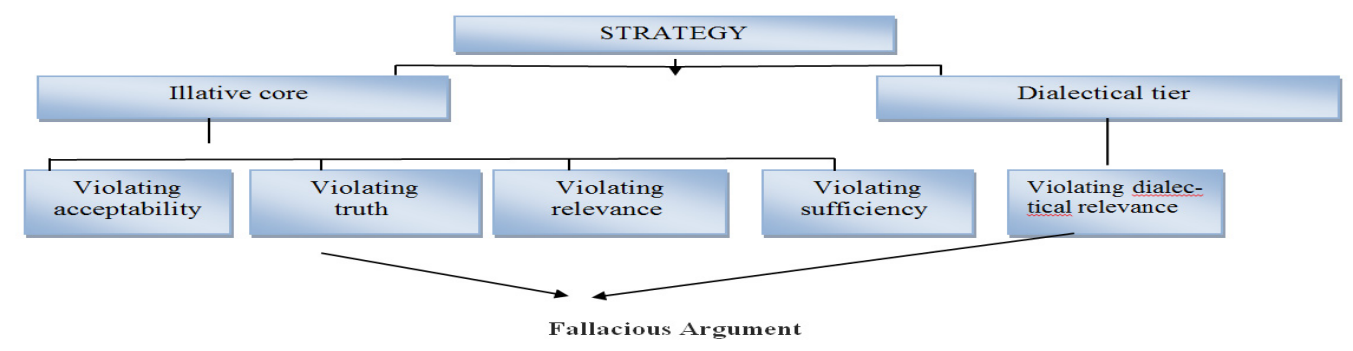

Figure 2. Pragmatic strategies of issuing a fallacious argument

\section{Developing the Pragmatic Model of Fallacy Analysis}

\subsection{The Pragmatic Structure of Fallacy}

As argued before, fallacy is the process of supporting an argument with another one that is considered defective for violating one or more of the rules of correctness for no reason but impressing the addressees to respond positively to that argument. This means that fallacy is composed of three stages. Each stage is distinct for its own devices and sub-stages. Generally speaking, these stages are: the start-point stage, the argument stage and the end point stage. The start-point stage embraces the topical potential sub-stage where the speaker introduces the topic to be discussed or proved. For this sub-stage, the speaker utilizes arguments which might be inductive or deductive. When scrutinizing the data under study, it seems that the start point stage includes another sub-stage which is called audience adaptation or audience orientation where the speaker employs two components: deixis and politeness.

At the second stage, the argument stage, the speaker issues the sub-stage of the fallacious argument which is structured of two pragmatic components: criteria of a good argument and the cooperative principle. However, it seems that the argument stage encompasses another sub-stage, i.e. the presentational devices sub-stage which is structured of two pragmatic components: rhetorical devices and principles of influence.

At the third stage, i.e. the end-point stage, the function of fallacy is tested to see whether it succeeds in persuading the addresses or not. At this stage comes the role of the addresses to evaluate and respond to the fallacious argument.

According to Walton (1995, p. 45), the addressees' response comes through questioning the argument by using the critical questions related to that argument. Such a type of response occurs in dialogical cases which are not of concern to the current study since the data scrutinized here are political speeches where the addressee has no right to respond linguistically as stated by Walton (2007, p. 65) who makes it clear that the addressee(s) can respond to any argument in these situations only non-linguistically. This claim is given some more detail in 3.2 .3 below.

Figure 3. below summarizes the pragmatic structure of the three stages of fallacy: 


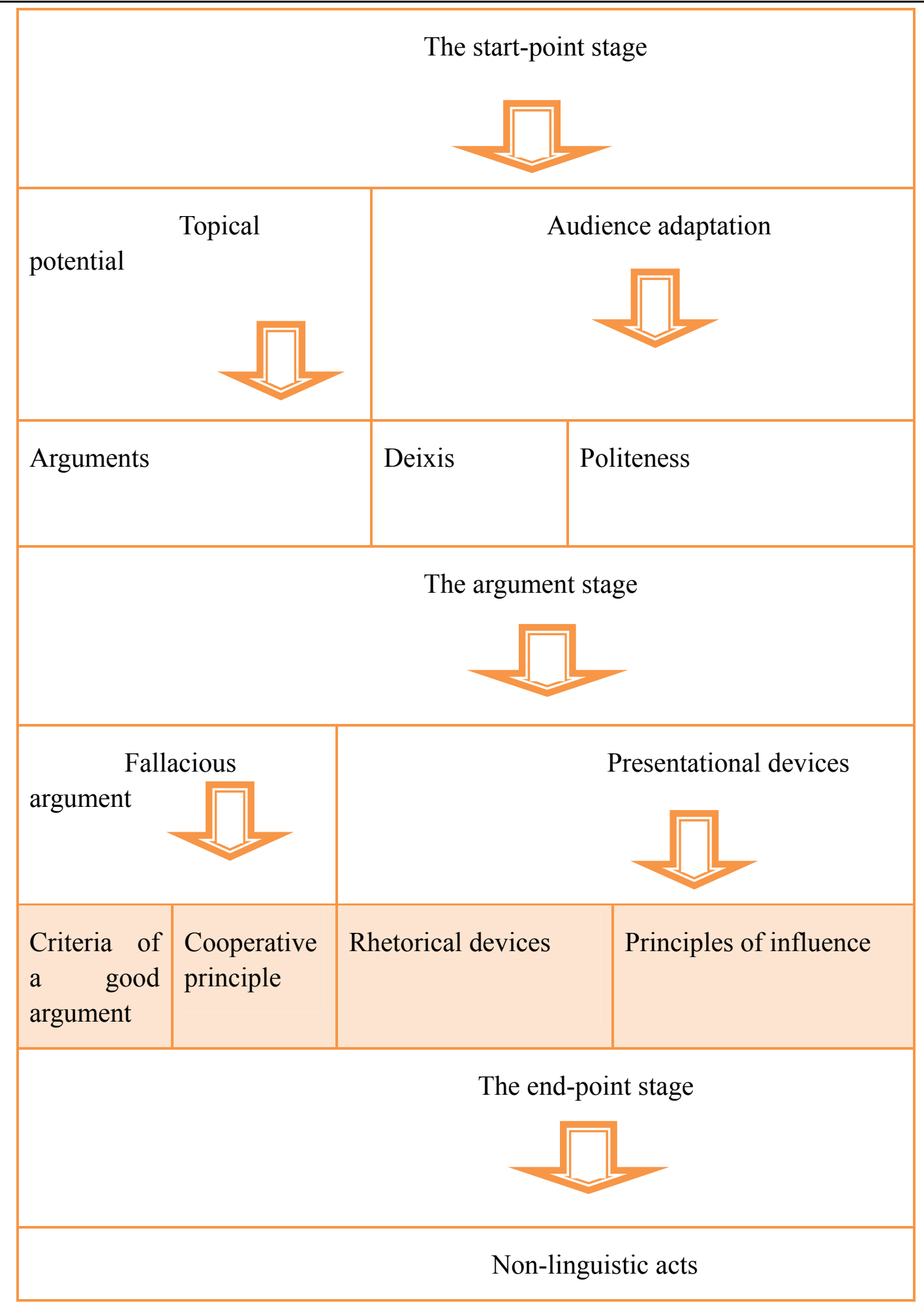

Figure 3 . The pragmatic structure of fallacy

\subsection{The Stages of Fallacy and Their Strategies}

Each of the three stages of fallacy is distinct for its components and strategies as illustrated in the following lines: 


\section{Macrothink}

\subsubsection{The Start-Point Stage}

This stage is composed of two sub-stages: topical potential and audience adaptation.

\section{a. Topical potential}

At the topical potential sub-stage, the topic to be discussed is introduced by the speaker. Speakers differ in the ways of topic introduction, but they mainly do so through utilizing arguments. The arguments at this stage are either inductive or deductive in type. They carry the claim that the arguer tries to support at the next stage through issuing the fallacious argument.

\section{b. Audience adaptation}

The second sub-stage, audience adaptation, manifests itself as indicated previously through deixis and politeness strategies.

\subsubsection{Deixis Strategies}

As for deixis, it is realized by first person deixis of integration employed to raise some sort of empathy and communion with the addressed group.

\subsubsection{Politeness Strategies}

\section{a. Claiming a Common Ground}

According to Brown and Levinson (1987) (Cited in Watts (2003, p. 89)), the speaker should realize that he and his addressees belong to some group of people who share specific wants, goals and values. This involves the speaker to show that some of the hearer's wants and desires are also desirable to him.

\section{b. Attending to Hearer's Interests}

This requires the speaker to notice the hearer's wants and needs and behave accordingly (Watts, 2003, p. 89).

\section{c. Seeking Agreement}

In order to gain the hearer's empathy, the speaker should agree with what the addressees want or say whatever it is. One of the best strategies of seeking agreement is through raising safe topics (Watts, 2003, p. 89).

\section{d. Being Indirect}

Directness causes threat to the hearer's face so the speaker should be indirect in order to avoid such threats (Watts, 2003, p. 90).

\section{e. Minimizing Imposition}

This strategy involves minimizing the possible imposition carried by the utterance of the speaker. This comes through appealing to certain expressions like (just, exactly, only, merely...etc.) or through intonation or through being indirect (Watts, 2003, p. 90). 
f. Being pessimistic

This involves showing pessimism towards what the speaker wants the hearer to do (Watts, 2003, p. 90).

\subsubsection{The Argument Stage}

This stage embraces two sub stages: the fallacious argument sub-stage and the presentational devices.

\section{a. The Fallacious Argument}

Whether an argument is fallacious or not, it should be judged on two levels:

\subsubsection{The Dialectical Tier}

The dialectical tier refers to the argument within a structure of dialogue.

\subsection{Criteria of identifying the Fallacious Argument on the Dialectical Tier}

Walton (1995, p. 163) proposes dialectical relevance for testing fallacious arguments of the dialectical tier. According to Walton (1995, p. 163), an argument is dialectically relevant if it contributes something to the goals of the context in which it occurs.

\subsection{Pragmatic Strategies of Issuing Fallacious Arguments on Dialectical Tier}

At this level, there is one main strategy of issuing the fallacious argument which is violating dialectical relevance. When the argument is irrelevant to the preceding argument(s) that it is intended to support, fallacious arguments of dialectical relevance occur.

\subsubsection{The Illative Core}

The illative core refers to the internal structure of the argument.

\subsubsection{Criteria for Identifying Fallacious Arguments on the Illative Core}

The criteria put for judging fallacious arguments of the illative core are proposed by Johnson (2000, p. 190). These are the following:

\section{a. The Acceptability criterion}

According to this criterion, the propositional content of the argument is judged to see whether it can be accepted by the intended audience or not.

\section{b. $\quad$ The Truth Criterion}

This criterion judges the truth versus the falsity of the premises of the argument, if they are truthful, the argument is good and if they are false, the argument is fallacious.

\section{c. The Relevance Criterion}

According to this criterion, the argument is propositionally judged to see whether its premises are relevant to each other or not. 


\section{d. The Sufficiency Criterion}

This criterion determines judging the argument to see if the evidence is sufficient enough to prove the claim or not.

\subsection{Pragmatic Strategies of Issuing Fallacious Argument at the Illative Core}

On the illative core, the arguer commits a fallacious argument if he follows one of the following strategies:

\subsection{Violating the Acceptability Criterion}

An argument is said to be fallacious if it violates the acceptability criterion.

\subsection{Violating the Truth Criterion}

An argument is regarded as fallacious if any of its premises is false or untruthful.

\subsection{Violating the Relevance Criterion}

Another strategy for committing fallacious argument is violating the relevance criterion.

\subsection{Violating the Sufficiency Criteria}

The last strategy of committing fallacious argument is violating the sufficiency criteria.

\section{b. Presentational Devices}

The second sub-stage, the presentational devices, encompasses two components: rhetorical devices and principles of influence.

\section{i. Rhetorical devices strategies}

Generally speaking, politicians employ three devices: padding, weasel words and profound words.

\section{ii. Principles of influence strategies}

As for principles of influence, it is observed that politicians appeal to: fear, interest, flattery, commitment, reciprocity, authority.

\subsubsection{The End-point Stage}

This stage is associated with testing the effect of the fallacious argument on the addressee. It has already been mentioned that fallacious arguments have a persuasive function. They are issued by the arguer as means of influencing the addressee to do or accept something. At this stage, the addressee shows his evaluation and response to such arguments. Their response is shown through non-linguistic acts in mono-logical situations. The main non-linguistic acts used by the audience in such situations are: cheer applause, agreement nods, and acts, looks of fear and agreement nods.

On the basis of the discussion above, the model developed here can be schematized by Figure 4. below: 
Thus, as illustrated in the discussion and figure above, fallacy is a process that moves dynamically on three stages: the Start point stage (SPS), the argument stage (AS), and the end-point stage (EPS). It is at the second stage, that strategic maneuvering gets derailed. This derailment comes through decreasing reasonableness and increasing effectiveness. Reasonableness gets diminished through violating (relevance, truth, acceptability, sufficiency, dialectical relevance) for persuasive purposes. Meanwhile, effectiveness gets upper hand on reasonableness through using excessively rhetorical devices and principles of influence.

\section{Data and Analysis}

\subsection{Data collection and Description}

The data collected for the analysis conducted here are represented by (14) fallacious situations chosen from (6) war and electoral political speeches as a whole delivered by David Cameron. These data are characterized by the following features:

\section{Genre}

The data are political speeches where the politician is the only speaker. This doesn't mean that there is no interaction between the speaker and his addresses as there is a simple kind of interaction represented by a word of praise or complaint. However, the response of the audience is mainly of the non-verbal kind like cheer applause, facial sympathy, laughter...etc.

\section{Length}

The speeches under study vary in length. Their length ranges from four to twenty pages.

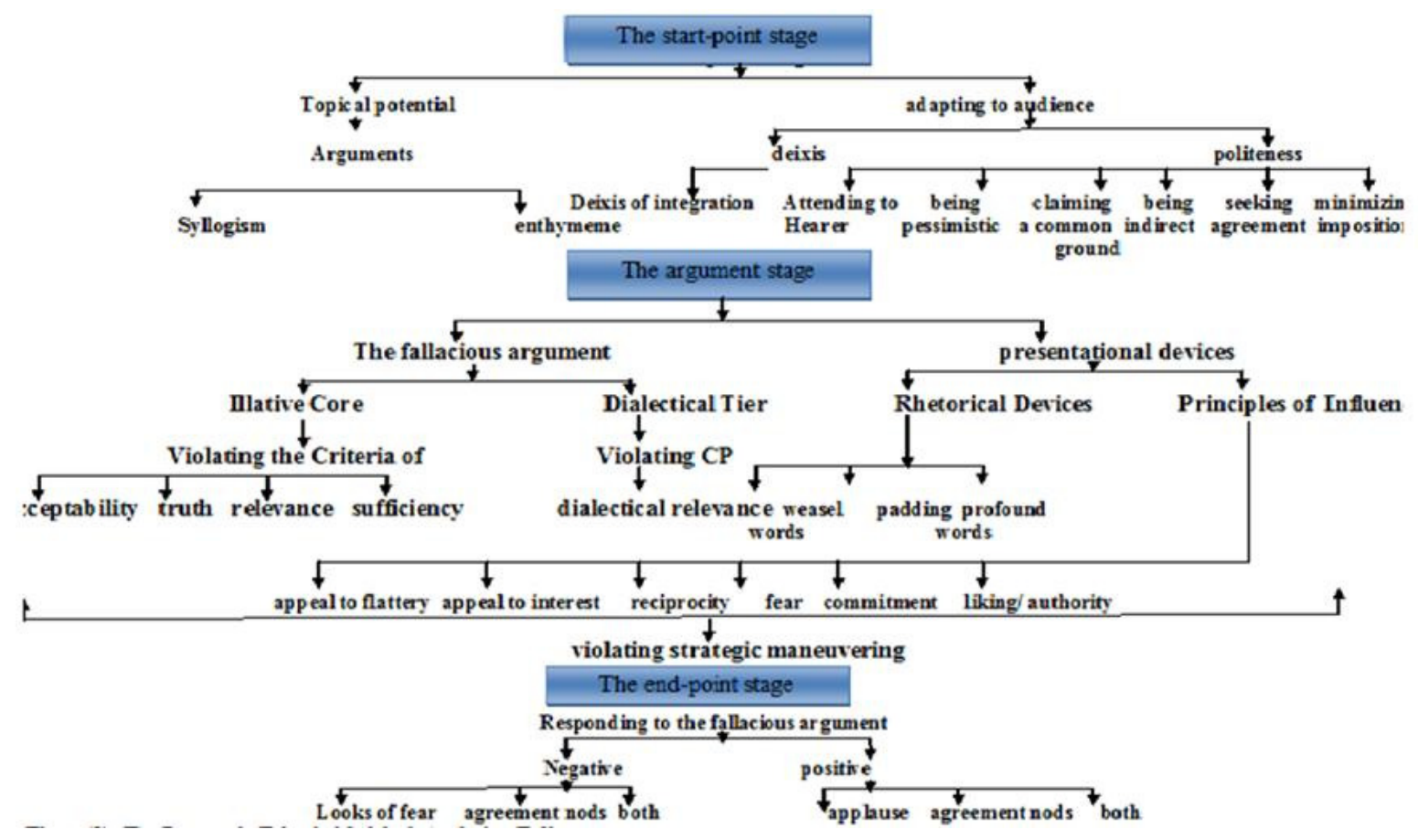

Figure 4. The eclectic pragmatic model of analyzing fallacy 


\section{Theme}

The main themes of the data of this work are election and war. This doesn't exclude tackling other themes. For example, while the politician is trying to convince the audience to give him support in election, he may discuss the healthcare or social system and how he is going to bring change to them.

\section{Form}

All political speeches are scripted and video-recorded. In this study, both forms (scripts and videos) are considered. This is so because scripts often ignore the audience non-linguistic responses to the fallacious arguments which are important in indicating the third stage of fallacy- the response stage.

\subsection{Analysis}

\subsubsection{Methods of Analysis}

The model developed in Section (3) will be the means of analyzing the pragmatic structure as well as the pragmatic strategies of fallacy in the political speeches under study. As for the statistical method of analysis, the percentage equation will be the basic instrument to vindicate the findings of the analysis.

\subsubsection{Overall Analysis}

\subsubsection{Pragmatic Structure}

The analysis of the pragmatic structure of the fallacious situations in David Cameron's speeches reveals that fallacy is a process composed of three stages: the start-point stage (SPS), the argument stage (AS), and the end-point stage (EPS). Each one of these stages is composed of pragmatic components. SPS is composed of arguments, deixis and politeness with each of which realized by certain strategies (See 4.2.2.2.).

The analysis of the second stage reveals that four pragmatic components represent its pragmatic construct: criteria of a good argument, the 'cooperative principle' (CP), rhetorical devices, and principles of influence (See also 4.2.2.2.). As for the EPS, non-linguistic acts form its pragmatic structure which is realized by different strategies (See 4.2.2.2). The findings of this analysis fulfill the first aim of this study and verify the first hypothesis. The rates of the pragmatic components of fallacy in David Cameron's speeches are best illustrated Table 1. and Figure 5. below: 
Table 1. Pragmatic structure of fallacy in David Cameron's speeches calculated in percentages

\begin{tabular}{|c|c|c|c|}
\hline \multirow{3}{*}{ The SPS } & $\mathrm{TP}$ & Arguments & $100 \%$ \\
\hline & \multirow{2}{*}{$\mathrm{AA}$} & Deixis & $78.571 \%$ \\
\hline & & Politeness & $85.714 \%$ \\
\hline \multirow{4}{*}{ The $A S$} & \multirow{2}{*}{ FA } & Criteria of a good argument & $100 \%$ \\
\hline & & $\mathrm{CP}$ & $0 \%$ \\
\hline & \multirow{2}{*}{$\mathrm{PD}$} & Rhetorical devices & $85.714 \%$ \\
\hline & & Principles of influence & $64.285 \%$ \\
\hline \multirow{2}{*}{ The EPS } & Non-linguistic & & \\
\hline & Acts & & $100 \%$ \\
\hline
\end{tabular}

Key: SPS=Start point stage, $\mathrm{AS}=$ argument stage, $\mathrm{EPS}=$ end-point stage, $\mathrm{TP}=$ Topical potential, $\mathrm{AA}=$ Audience Adaptation, $\mathrm{FA}=$ Fallacious Argument, $\mathrm{PD}=$ Presentational devices, $\mathrm{IA}=$ Inductive argument, $\mathrm{DA}=$ Deductive Argument.

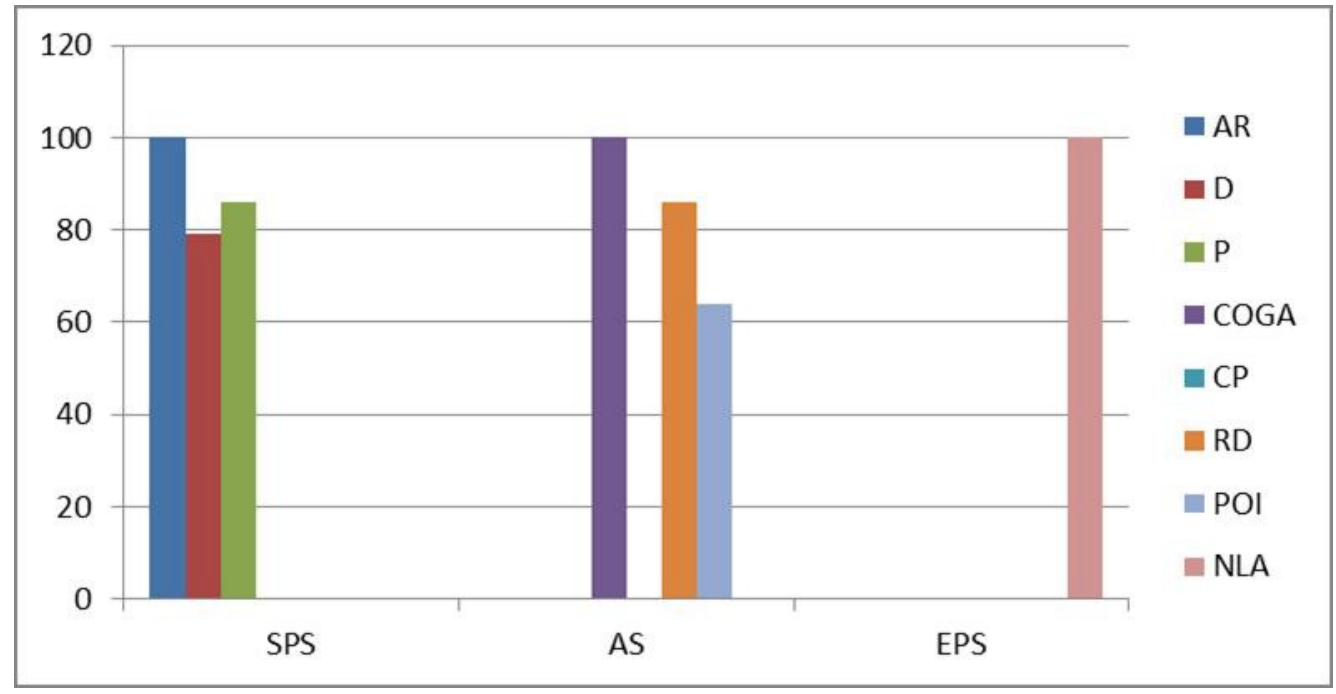

Figure 5. Rates of the pragmatic components of fallacy in David Cameron's speeches

\subsubsection{Pragmatic Strategies}

The analysis of the pragmatic strategies reveals the following:

1. The strategies employed in SPS stage are: first person deixis $78.571 \%$, being indirect $27.777 \%$, attending to hearer $22.222 \%$, being pessimistic $22.222 \%$, minimizing imposition $14.285 \%$, seeking agreement $11.111 \%$, claiming a common ground $5.555 \%$. These findings 


\section{Mll Macrothink}

fulfill the second aim of this study and verify the second hypothesis (See also Table 2 and Figure 6 below).

2. At the AS stage, the analysis reveals that the strategies realizing the criteria of a good argument have the following frequencies: violating relevance $57.142 \%$, violating sufficiency $35.714 \%$, violating acceptability $21.428 \%$, violating truth $0 \%$, violating dialectical relevance $0 \%$. As for the strategies of rhetorical devices, they are the following: profound words $75 \%$ padding $18.75 \%$, weasel words $6.25 \%$. Concerning the strategies of principles of influence, the analysis reveals that they are the following: appealing to interest $60 \%$, appealing to fear $20 \%$, commitment $10 \%$, flattery $10 \%$, reciprocity $0 \%$, authority $0 \%$. These findings fulfill the second aim of this study and verify the second hypothesis (See Table 2. and Figure 6 below).

3. In the EPS, the addressees employ all the strategies that can be used but with different percentages: cheer applause 35.714\%, agreement nods $28.571 \%$, cheer applause and agreement nods $14.285 \%$, agreement nods and looks of fear $14.285 \%$, looks of fear $7.142 \%$. These findings fulfill the second aim of this study and verify the second hypothesis (See Table 2 and Figure 6 below).

Table 2. The pragmatic strategies employed at the three stages of fallacy in David Cameron's speeches calculated in percentages

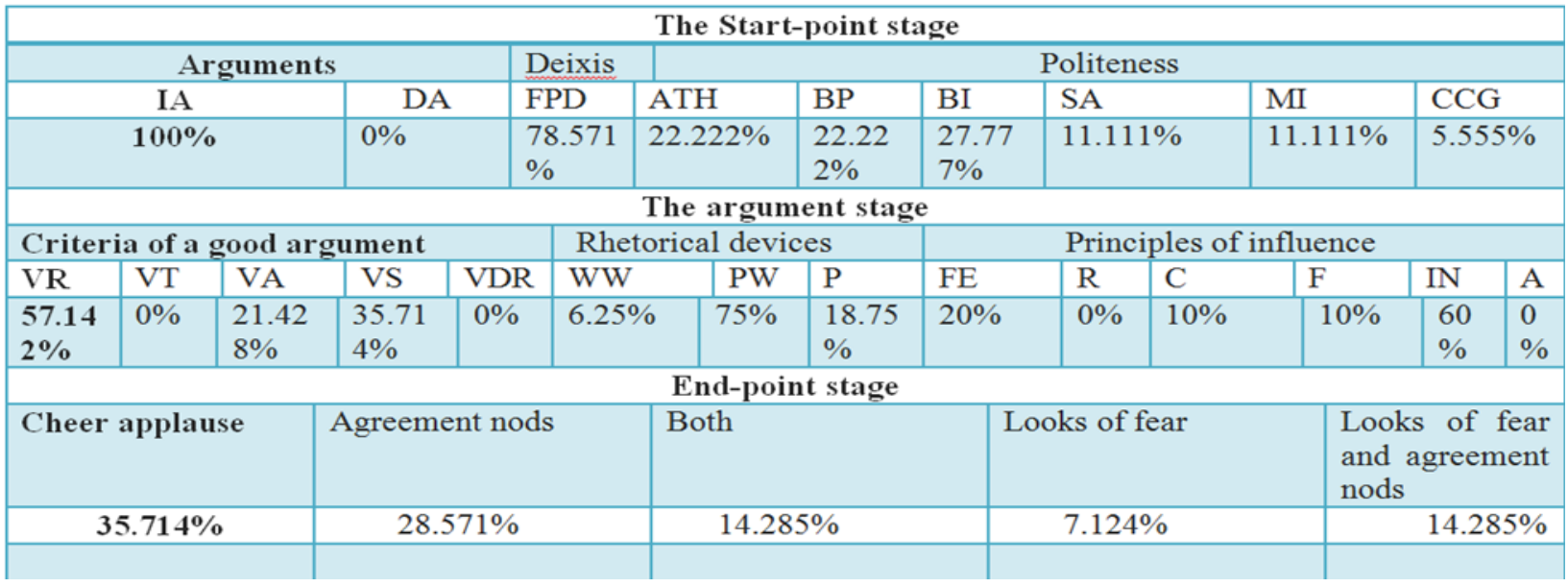

Key: IA=Inductive Argument, $\mathrm{DA}=$ Deductive argument, $\mathrm{FPD}=$ first personal deixis, $\mathrm{ATH}=$ Attending to hearer, $\mathrm{BP}=$ being pessimistic, $\mathrm{BI}=$ being indirect, $\mathrm{SA}=$ seeking agreement, $\mathrm{MI}=$ minimizing imposition, $\mathrm{CCG}=$ claiming a common ground, $\mathrm{VT}=$ violating truth, $\mathrm{VR}=$ violating relevance, $\mathrm{VA}=$ violating acceptability, $\mathrm{VS}=$ violating sufficiency, $\mathrm{WW}=$ weasel words, $\mathrm{PW}=$ profound words, $\mathrm{P}=$ Padding, $\mathrm{FE}=$ Fear, $\mathrm{R}=$ reciprocity, $\mathrm{C}=$ commitment, $\mathrm{F}=$ flattery, $\mathrm{IN}=$ interest, $\mathrm{A}=$ authority. 


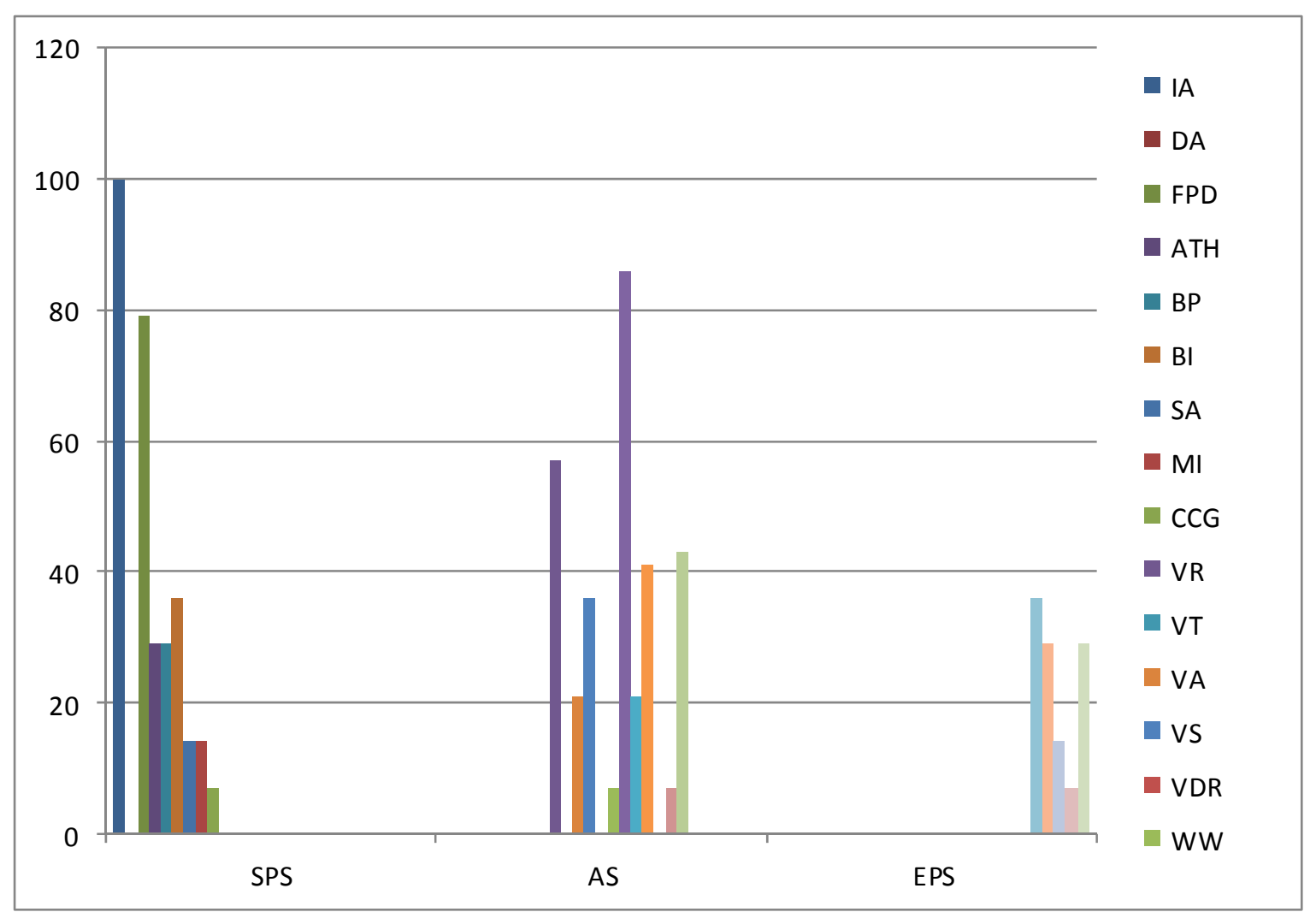

Figure 6. The pragmatic strategies employed at the three stages of fallacy in David Cameron's speeches calculated in percentages

\subsubsection{Illustrative Analyzed Examples}

\section{$\underline{\text { Situation (1) }}$}

The reason we want to reform schools, to cut welfare dependency, to reduce government spending is not because we're the same old Tories who want to help the rich. We're the Tories whose ideas help everyone - the poorest the most.

There is only one real route out of poverty and it is work.

\section{Cheer applause and agreement nods.}

(web source).

The fallaciousness of this situation Stems from violating the acceptability criterion (See the AS stage below).

The SPS, in this example, is triggered via the TP activated by issuing an inductive argument "The reason we want to reform schools, to cut welfare dependency, to reduce government spending is not because we're the same old Tories who want to help the rich. We're the Tories whose ideas help everyone - the poorest the most", combined with the AA which is initiated by two pragmatic components: deixis and politeness. Deixis is represented by using the first 
person deictic expression "we" used to create some sort of empathy and communion with the addressees.

Politeness is actualized by using the strategy of attending to the hearers with promises like "we want to reform schools, to cut welfare dependency, to reduce government spending is not because we're the same old Tories who want to help the rich. We're the Tories whose ideas help everyone - the poorest the most" and the strategy of seeking agreement through raising such a topic.

In the AS, David Cameron, the fallacy-maker, commences the fallacious argument sub-stage through the employment of the criteria of a good argument actualized through violating the acceptability criterion.

The fallaciousness of this argument results from presenting unacceptable claim. Despite the fact that both the speaker and the addressees know that there are different ways of overcoming poverty other than work, the speaker moves to the "white-black" way of arguing which is either work or remain poor, restricting in that the number of alternatives available to his addressees.

The presentational devices sub-stage is initiated through using two pragmatic components: pragma-rhetorical devices and principles of influence. Rhetorical devices are represented by using profound words like: "only", "real", "route" to help keeping persuasive. The principles of influence comprise the strategy of appealing to the hearer's interests in overcoming poverty.

The violation of the acceptability criterion, i.e. the diminishment of reasonableness and the excessive use of the means of persuasion (rhetorical devices and principles of influence) has led to the derailment of strategic maneuvering.

The EPS is commenced through utilizing non-linguistic acts realized by cheer applause and agreement nods.

The findings of this analysis accord with those arrived at in (4.2.2.1) and (4.2.2.2) and are compatible with those listed in Tables (1) and (2) and sketched in Figures 5. and 6. Together, they fulfill the first and second aims of this study and verify the first and second hypotheses.

\section{Situation (2)}

But success will come: with the right ideas, the right approach, the right leadership. Leadership from government: to set out the direction we must take, and the choices we must make. But leadership also from you. The things that will really deliver success are not politicians or government. It's the people of Britain, and the spirit of Britain.

Some say that to succeed in this world, we need to become more like India, or China, or Brazil. I say: we need to become more like us. The real us. Hard-working, pioneering, independent, creative, adaptable, optimistic, can-do. That's the spirit that has made this United Kingdom what it is: a small country that does great things; one of the most incredible success stories in the history of the world. 
(cheer applause). (Web source).

This situation is fallacious because the speaker violates the relevance criterion. This violation is best illustrated at the AS stage below.

The SPS consists of three pragmatic components, viz. arguments, deixis and politeness distributed over two sub-stages as follows: the TP sub-stage contains the inductive argument: "But success will come: with the right ideas, the right approach, the right leadership. Leadership from government: to set out the direction we must take, and the choices we must make. But leadership also from you. The things that will really deliver success are not politicians or government. It's the people of Britain, and the spirit of Britain".

The AA sub-stage is composed of the element of deixis realized by the first person deixis of integration "we"; and the element of politeness realized by two strategies: seeking agreement through raising such a safe topic and through the strategy of being pessimistic in claiming that "The things that will really deliver success are not politicians or government. It's the people of Britain, and the spirit of Britain".

The second stage, the AS, is composed of three pragmatic components distributed over two sub-stages and are illustrated as follows: the FA sub-stage embraces the criteria of a good argument represented by violating the relevance criterion.

The speaker presents data that touch the addressees emotions rather than reasonably support the claim and this occurs on the illative core of the argument not the dialectical tier.

The PD sub-stage is composed of two pragmatic components: pragma-rhetorical devices and principles of influence. The pragma-rhetorical devices are realized by two strategies: profound words "creative", "pioneering", "can-do", "great", "small", "incredible"; and the second strategy is padding which becomes clear in the speaker's statement "we must become more like us" and adding "the real us" which adds nothing or little to the meaning of the previous construction but it just emphasizes it for rhetorical purposes.

The principles of influence are actualized by the strategy of appealing to flattery in stating that " we need to become more like India, or China, or Brazil. I say: we need to become more like us. The real us. Hard-working, pioneering, independent, creative, adaptable, optimistic, can-do. That's the spirit that has made this United Kingdom what it is: a small country that does great things; one of the most incredible success stories in the history of the world".

The violation of the relevance criterion, i.e. the diminishment of reasonableness and the excessive use of means of persuasion (rhetorical devices and principles of influence) has led to the derailment of strategic maneuvering.

The EPS is composed of one element, the non-linguistic acts embodied by responding with cheer applause which indicates that the fallacious argument has been received as being persuasive.

The findings of this analysis accord with those arrived at in (4.2.2.1.) and (4.2.2.2.) and are compatible with those listed in Tables (1) and (2) and sketched in Figures (5) and (6). 
Together, they fulfill the first and second aims of this study and verify the first and second hypotheses.

\section{Situation (3)}

Britain is an open, tolerant and free nation. We are a country that backs people in every community, who want to work hard, make a contribution and build a life for themselves and their families. But we cannot stand by and allow our openness to be confused with a tolerance of extremism, or one that encourages different cultures to live separate lives and allows people to behave in ways that run completely counter to our values.

Adhering to British values is not an option or a choice; it is a duty for those who live in these islands. And in the end it is only by standing up for these values that will defeat the extremism, protect our way of life and keep all our people safe.

Agreement nods. (Web source)

This situation is fallacious because the speaker violates the relevance criterion in presenting, as evidence to his claim, data appealing to the addressees' values rather than supporting the claim. (See the AS stage below).

The SPS contains three pragmatic components: arguments, deixis, and politeness distributed over two sub-stages: TP and AA. The TP sub-stage is initiated by issuing the inductive argument: "Britain is an open, tolerant and free nation. We are a country that backs people in every community, who want to work hard, make a contribution and build a life for themselves and their families. But we cannot stand by and allow our openness to be confused with a tolerance of extremism, or one that encourages different cultures to live separate lives and allows people to behave in ways that run completely counter to our values".

The AA sub-stage includes two pragmatic components: deixis and politeness. As for deixis, the speaker utilizes the strategy of using the first person deixis "we" to raise some spirit of communion with those he is addressing.

Concerning politeness, the speaker utilizes two pragmatic strategies. The first is being indirect in asking them, invoking their values, to fight extremism. The second strategy is attending to their interests in adhering to their values.

In the subsequent AS, the fallacy-maker David Cameron commences FA actualized by violating the criterion of relevance.

The criterion of relevance is violated when the speaker invokes the values of the addressees as a support to his claim instead of presenting the evidence relevant to that claim.

In addition to the FA, the speaker issues the PD utilizing the component of rhetorical devices realized by the strategy of using profound words like: duty, option, standing up, all, and safe. The other strategy is using weasel words like: only.

The violation of the relevance criterion, i.e. the diminishment of reasonableness and the excessive use of means of persuasion (rhetorical devices and principles of influence) has led 
to the derailment of strategic maneuvering.

The EPS is triggered via non-linguistic acts represented by the strategy of making agreement nods to indicate the acceptance of the fallacious argument as being persuasive.

The findings of this analysis accord with those arrived at in (4.2.2.1.) and (4.2.2.2.) and are compatible with those listed in Tables (1) and (2) and sketched in Figures 5. and 6. Together, they fulfill the first and second aims of this study and verify the first and second hypotheses.

\section{Conclusions}

On the basis of the analysis conducted, the following conclusions can be introduced:

1. Arguments, deixis, politeness, criteria of a good argument, CP, rhetorical devices, principles of influence and non-linguistic acts are all components of the issuance process of fallacy as reflected by David Cameron.

2. Issuing fallacy comes through employing various strategies. Each stage is different from the others in the strategies the fallacy-maker employs.

3. As for the first stage, the fallacy-maker here, i.e. David Cameron makes use of two kinds of strategies: deixis strategies and politeness strategies. Deixis is realized by first person deixis 'we', politeness is realized by (attending to hearers, being indirect, being pessimistic, minimizing imposition, seeking agreement, claiming a common ground).

4. At the second stage, the fallacy maker employs four kinds of strategies: criteria of a good argument strategies, cooperative principle strategies, rhetorical devices strategies and principles of influence strategies. Criteria of a good argument strategy are (violating relevance, violating acceptability, violating truth, violating sufficiency). $\mathrm{CP}$ strategies are violating dialectical relevance. Concerning rhetorical devices strategies, the analysis reflects that the ones appealed to here are (padding, weasel words, and profound words). As for principles of influence strategies, they are appealing to (fear, interest, flattery, reciprocity, authority, commitment).

5. At the third stage, the strategies employed by the addressees as signs of response are of non-linguistic acts which include: (cheer applause, agreement nods, both of the preceding strategies, looks of fear, looks of fear, and agreement nods).

6. The workability of the model developed for the analysis of the data has been proven and all the hypotheses of the study have been verified in terms of the findings of the analysis conducted in this regard.

\section{References}

Beard, A. (2000). The language of politics. London: Routledge.

Brydon, S., \& Scott, M. (2008). Between one and many. New York: Frank Mortimer.

Cavender, N. M., \& Kahane, H. (2006). Logic and contemporary rhetoric. Oxford: Wordsworth. 
Eemeren, F. H. van, \& Grootendorst, R. (1999). Speech acts in argumentative discussions: A theoretical model for the analysis of discussions directed towards solving conflicts of opinion. Berlin: De Gruyter. http://dx.doi.org/10.1515/9783110846089

Eemeren, F. H. van, \& Houtlosser, P. (1999). Strategic manoeuvering in argumentative discourse. Discourse Studies, 1, 479-497. http://dx.doi.org/10.1177/1461445699001004005

Eemeren, F. H. van, \& Houtlosser, P. (2000). Rhetorical analysis within a pragma-dialectical framework. Argumentation, 14, 293-305. http://dx.doi.org/10.1023/A:1007857114100

Eemeren, F. H. van, \& Houtlosser, P. (2002). Strategic maneuvering: maintaining a delicate balance. In F. H. van Eemeren, \& P. Houtlosser (Eds.), Dialectic and rhetoric: the warp and woof of argumentation analysis, pp. 131-159. Dordrecht: Kluwer Academic. http://dx.doi.org/10.1007/978-94-015-9948-1_10

Eemeren, F. H. van, Garssen, B., \& Meuffels, B. (2009). Fallacies and judgments of reasonableness. London: Springer. Grice, H. P. (1975). "Logic and conversation". In P. Cole \& J. Morgan (Eds.), Syntax and Semantics, 3, 41-58. New York, NY: Academic Press.

Grice, H. P. (1975). Logic and conversation. In P. Cole, \& J. Morgan, (Eds.), Syntax and semantics, 3, 41-58. New York, NY: Academic Press.

Hamblin, C. L. (1970). Fallacies. London: Richard Clay Ltd.

Johnson, R. (2000). Manifest rationality: a pragmatic theory. Mahwah, NJ: Lawrence Erlbaum Associates, Inc.

Krabbe, Erik C. W. (1992). So what? Profiles for relevance criticism in persuasion dialogues. Argumentation, 6, 271-283. http://dx.doi.org/10.1007/BF00154330

Ramage, J. D. (2010). Writing arguments. Oxford: Pearson Education.

Tindale, W. (1999). Fallacies and argument appraisal. Cambridge: Cambridge University Press.

Watts, R. (2003). Politeness. Cambridge: Cambridge University Press. http://dx.doi.org/10.1017/CBO9780511615184

Walton, D. (1995). A Pragmatic theory of fallacy: Studies in rhetoric and communication. London: University of Alabama Press.

Walton, D., \& Reed, C. (2003). Argumentation schemes in argument as a process and argument as a product. In J. Anthony et al. (Eds), Proceedings of the Windsor Conference. Windsor, Ontario: Ossa.

Walton, D. (2007). Media argumentation: dialectic, persuasion and rhetoric. Cambridge: Cambridge University Press. http://dx.doi.org/10.1017/CBO9780511619311

Web source (online). David Cameron@ British Rhetoric.com 


\section{Copyright Disclaimer}

Copyright reserved by the author(s).

This article is an open-access article distributed under the terms and conditions of the Creative Commons Attribution license (http://creativecommons.org/licenses/by/3.0/). 